\title{
A New Method for Studying Working Memory by Using the Three-Panel Runway Apparatus in Rats
}

\author{
Yoshiaki FURUYA*, Tsuneyuki YAMAMOTO**, Shin-ichi YATSUGI \\ and Showa UEKI
}

Department of Pharmacology. Faculty of Pharmaceutical Sciences, Kyushu University 62. Fukuoka 812. Japan

Accepted November 4, 1987

\begin{abstract}
We designed a new method for studying working memory, by using a repeated acquisition procedure in the three-panel runway apparatus. This apparatus is composed of a start box, a goal box and four consecutive choice points: each choice point consists of three panel gates. Male Wistar rats were trained with 6 consecutive trials (one session) per day. Each trial was performed every two minutes. In this apparatus, rats could pass through only one gate (correct gate) among three panel gates in the direction of the goal box and were given $100 \mathrm{mg}$ food pellets as the positive reinforcement. The sequence of correct gate position in each rat was changed everyday, but not in each session. Error responses (pushing the incorrect gate) were gradually reduced as training was repeated, and the learning was established within 16 training sessions to achieve criterion performance. Intraperitoneal scopolamine and intrahippocampal ethylcholine aziridinium ion (AF64A) produced increases in both the number of errors and the latency in a dose-dependent manner. The increase in errors induced by AF64A did not return to the control level, though the prolonged latency returned to normal. As a conclusion, this experimental procedure using the three-panel runway apparatus would be a useful method for studying working memory, and its memory deficit is involved at least in the dysfunction of the cholinergic system in the hippocampus.
\end{abstract}

Delayed matching to sample procedure (DMTS) is frequently used for studying short-term memory or working memory $(1,2)$. In the rat experiment, there are usually two selections (right side or left side). so the chance level is high (50\%). It seems difficult for rats to acquire this task under a condition where the number of choices is more than two.

Recently, the radial maze is very often used for studying working memory. Nagni et al. (3) and Watts et al. (4) have reported that each subject has the choice pattern to gain food-pellets. If the subject gains pellets in the similar order day after day, the data reflect

- Present address: Tsukuba Research Laboratories, Eisai Co., Ltd., 1-3 Tokodai 5-chome. Tsukuba, |baraki 300-26. Japan

** To whom all correspondence should be addressed. reference memory rather than working memory.

So, we designed a new method for studying working memory, using the panel runway apparatus which has four consecutive choice points. In this experiment, we performed the fundamental studies on this runway task and examined the influence of a cholinergic neurotoxin, ethylcholine aziridinium ion (AF64A) (5), and an anticholinergic agent, scopolamine, on runway performance.

\section{Materials and Methods}

Subjects: Male rats of the Wistar KY strain were used, and they were approximately 10 weeks old and weighed $250 \mathrm{~g}$ at the start of food deprivation. Their body weights were maintained at approximately $80 \%$ of the free feeding level during the experimental period. except during the three days following 
surgery. Water was freely available in their home cages. Rats were housed in groups of four to six per cage, under a constant temperature $\left(23 \pm 2^{\circ} \mathrm{C}\right)$ with a $12 \mathrm{hr}$ light-dark cycle (light on: 7:00-19:00).

Apparatus: We used the runway apparatus, a modified Hill's one (6). This apparatus is made of vinyl chloride and composed of a start box, a goal box and four consecutive choice points (Fig. 1). Each choice point consists of three panel gates $(\mathrm{a}-\mathrm{c})$. Rats were prohibited from passing through two of the three gates in each choice point by a front stopper and prohibited from coming back to the start box by a rear stopper.

Acquisition training: Rats were preliminarily trained to run within $20 \mathrm{sec}$ from the start box to the goal box. At this time, all front stoppers were removed, and rats could pass through all panel gates. From the next day, rats were trained with 6 consecutive trials ( 1 session) per day under the condition that one of the three gates in each choice point could be passed through.

The sequence of correct panel gate positions for each rat was changed everyday, but not in each session. Twelve types of sequences were used in this experiment, as shown in Table 1. The latency, i,e., the time required for the rat to take the pellet, and the number of errors, i.e., the number of pushing incorrect gates, were recorded in every trial. The total errors and total latency displayed by each rat were indicated as the sum of 6 con-

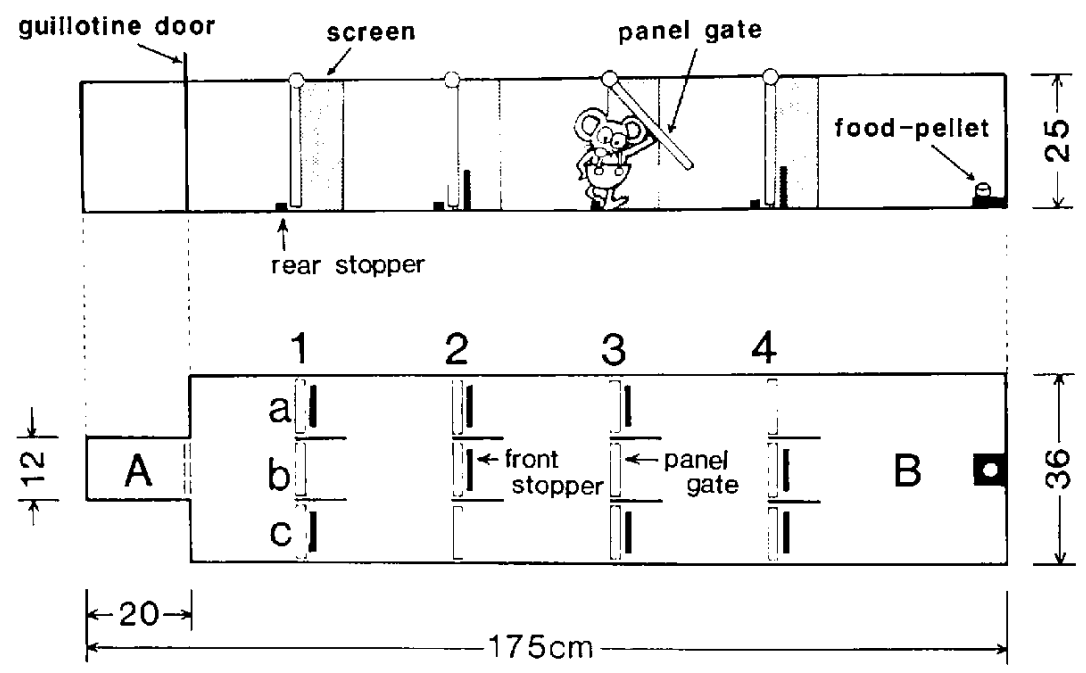

\section{A:start box B:goal box}

Fig. 1. Schematic drawing of the three-panel runway apparatus.

Table 1. Twelve types of sequences of correct panel position in the three-panel runway apparatus

\begin{tabular}{|c|c|c|c|c|c|c|c|c|c|}
\hline & \multicolumn{4}{|c|}{ choice point } & \multicolumn{5}{|c|}{ choice point } \\
\hline & 1 & 2 & 3 & 4 & & 1 & 2 & 3 & 4 \\
\hline 1. & $\mathrm{a}$ & b & a & $c$ & 7. & $c$ & a & & - a \\
\hline 2. & $c-$ & $\mathrm{b}$ & $c$ & $a$ & 8. & $b$ & $a$ & 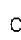 & b \\
\hline 3. & b. & c & $b$ & a & 9. & $b$ & $\mathrm{C}$ & a & - $\mathrm{C}$ \\
\hline 4. & $\mathrm{C}$ & a & $c$ & $b$ & 10 & $\mathrm{a}$ & $\mathrm{b}$ & 6 & $b$ \\
\hline 5. & $c$ & $b$ & a & $c$ & 11. & $b$ & a & 0 & - a \\
\hline 6. & $\mathrm{a}-$ & $\mathrm{C}$ & b & $c$ & 12. & $\mathrm{a}$ & C & & $a$ \\
\hline
\end{tabular}


secutive trials. We selected rats which attained the criteria that the mean of the total errors in three consecutive sessions was smaller than 12, and they were used to study the influence of 1) trial-trial intervals of 10 and $60 \mathrm{~min}$ and 2) anticholinergic drugs on this runway performance.

Drugs: (-)-Scopolamine hydrobromide (Sigma Chemical Co,) was dissolved in saline. Ethylcholine aziridinium ion (AF64A, from Eisai Co.) was prepared from acetylAF64 $\mathrm{HCl}$ as reported previously by Fisher et al. (7). Acetyl-AF64 $\mathrm{HCl}$ was quickly dissolved in distilled water. The preparation was adjusted to $\mathrm{pH} 11.5-11.7$ with $0.5 \mathrm{~N} \mathrm{NaOH}$ and maintained at $\mathrm{pH} 11.5-11.7$ for $20 \mathrm{~min}$. Then, the $\mathrm{pH}$ was reduced to $7.3-7.4$ with $0.2 \mathrm{~N} \mathrm{HCl}$. Distilled water was added to bring the final concentration of AF64A to 2.5 or $5.0 \mathrm{nmole} / \mathrm{ul}$. These solutions were left for one hour at room temperature and thereafter kept on ice until used.

Scopolamine and AF64A-administration: Twelve rats that had attained the criteria were used in the scopolamine experiment. At intervals of three days, three doses of scopolamine (0.32. 0.56 and $1.0 \mathrm{mg} / \mathrm{kg}$ ) were injected intraperitoneally in each rat in random order. The test was performed $20 \mathrm{~min}$ after the scopolamine injection. Between trials, water was freely available in their home cages for quenching their thirst.

(A)

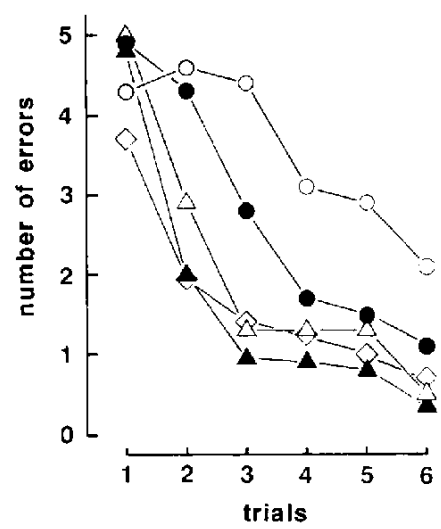

In the AF64A experiment, 18 rats that had attained the criteria were divided into three groups. Rats were anesthetized with sodium pentobarbital (35 mg/kg, i.p.: Pitman-Moore, Inc.). and the head was placed in a stereotaxic apparatus. The skull overlying the dorsal hippocampus was bilaterally trepanned. The microinjection apparatus consisted of a stainless steel injection needle connected to a $5 \mu \mathrm{l}$ Hamilton microsyringe via a polyethylene tube. Each $1.0 \mathrm{kl}$ of either AF64A solutions (2.5 or $5.0 \mathrm{nmole} / \mu \mathrm{l}$ ) or saline was injected bilaterally, at the rate of $1.0 \mu l$ per minute, into the dorsal hippocampus (anterior. -3.3 from the bregma; lateral. 2.8 from the midline; and ventral, 2.8 below the dura). The microinjection needle was removed $1 \mathrm{~min}$ after the completion of injection. Rats were freely fed for three days after the surgery to prompt them to recover. Thereafter, their body weights prior to surgery were maintained. From 11 days after the surgery. rats were subjected to one session per day for 15 consecutive days. Between trials. water was freely available in their home cage.

\section{Results}

Acquisition curve: The number of errors was gradually decreased from trial 1 to 5 (Fig. 2A). Total errors were reduced with repeated sessions and stabilized at about 10 errors after 5 sessions. On the other hand, the

(B)

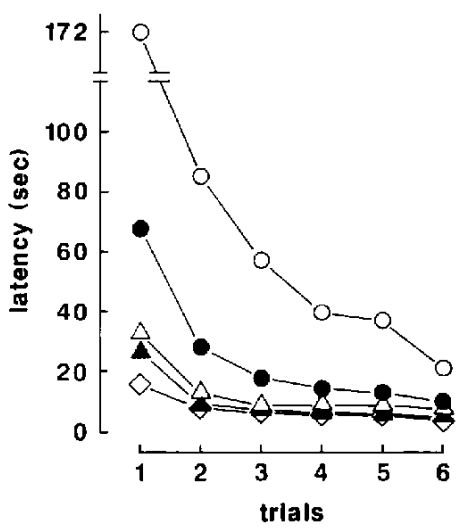

Fig. 2. Acquisition process in 6 consecutive trials of the runway performance. The trial-trial interval was 2 min. $\bigcirc-O 1$ st session, - - -2 nd session, $\Delta-\Delta$ 3rd session, $\mathbf{\Delta}-\mathbf{\Delta} 5$ th session. $\diamond->10$ th session. A: number of errors. B: latency (sec). 
Table 2. The effect of scopolamine on 3-panel gate runway performance as assayed by a repeated aquisition procedure

\begin{tabular}{|c|c|c|c|c|c|c|c|c|c|c|}
\hline \multirow{2}{*}{ Treatment } & \multirow{2}{*}{$\begin{array}{c}\text { Dose } \\
(\mathrm{mg} / \mathrm{kg})\end{array}$} & \multirow{2}{*}{$N$} & \multicolumn{7}{|c|}{ Number of errors in each trials (mean \pm S.E.M.) } & \multirow{2}{*}{$\begin{array}{c}\text { Total } \\
\text { latency }\end{array}$} \\
\hline & & & 1 & 2 & $\overline{3}$ & 4 & 5 & 6 & total & \\
\hline Saline & - & 8 & $\begin{array}{l}4.00 \\
\pm 0.46\end{array}$ & $\begin{array}{l}1.50 \\
\pm 0.27\end{array}$ & $\begin{array}{l}1.50 \\
\pm 0.38\end{array}$ & $\begin{array}{l}0.88 \\
\pm 0.30\end{array}$ & $\begin{array}{l}0.75 \\
\pm 0.41\end{array}$ & $\begin{array}{l}0.88 \\
\pm 0.44\end{array}$ & $\begin{array}{l}9.52 \\
\pm 1.30\end{array}$ & $\begin{array}{l}44.13 \\
\pm 3.65\end{array}$ \\
\hline \multicolumn{11}{|c|}{ Scopolamine } \\
\hline & 0.32 & 8 & $\begin{array}{l}4.50 \\
\pm 0.33\end{array}$ & $\begin{array}{l}3.00 \\
\pm 0.63\end{array}$ & $\begin{array}{l}2.00 \\
\pm 0.38\end{array}$ & $\begin{array}{l}1.88 \\
\pm 0.55\end{array}$ & $\begin{array}{l}1.88 \\
\pm 0.64\end{array}$ & $\begin{array}{l}0.88 \\
\pm 0.35\end{array}$ & $\begin{array}{l}14.13 \\
\pm 2.35\end{array}$ & $\begin{array}{l}80.63 \\
\pm 18.26\end{array}$ \\
\hline & 0.56 & 8 & $\begin{array}{l}5.00 \\
\pm 0.57\end{array}$ & $\begin{array}{l}3.88 \\
\pm 0.35^{* * *}\end{array}$ & $\begin{array}{l}3.00 \\
\pm 0.57^{*}\end{array}$ & $\begin{array}{l}2.38 \\
\pm 0.38 * *\end{array}$ & $\begin{array}{l}2.63 \\
\pm 0.50^{*}\end{array}$ & $\begin{array}{l}2.13 \\
\pm 0.40\end{array}$ & $\begin{array}{l}19.0 \\
\pm 1.75 * * *\end{array}$ & $\begin{array}{l}113.63 \\
\pm 22.36\end{array}$ \\
\hline & 1.0 & 8 & $\begin{array}{l}4.63 \\
\pm 0.42\end{array}$ & $\begin{array}{l}4.00 \\
\pm 0.71^{*}\end{array}$ & $\begin{array}{l}4.00 \\
\pm 0.33^{* * *}\end{array}$ & $\begin{array}{l}4.00 \\
\pm 0.80^{* *}\end{array}$ & $\begin{array}{l}3.63 \\
\pm 0.80^{* *}\end{array}$ & $\begin{array}{l}3.50 \\
\pm 0.60^{* *}\end{array}$ & $\begin{array}{l}23.75 \\
\pm 2.38^{* * *}\end{array}$ & $\begin{array}{l}136.00 \\
\pm 25.50^{*}\end{array}$ \\
\hline
\end{tabular}

$* P<0.05, * * P<0.01, * * P<0.001$

latency was also reduced by repeated sessions and stable from session 5 (Fig. 2B). At this time. the total latency was about $40 \mathrm{sec}$.

In error responses from trial 1 to trial 6 , there was no significant difference among three groups with trial-trial intervals of 2, 10 and $60 \mathrm{~min}$ (analysis of variance). The total errors in the groups with trial-trial intervals of 2. 10 and $60 \mathrm{~min}$ was $9.89 \pm 1.40$ (mean \pm S.E.M.; $N=9), \quad 12.00 \pm 2.17(N=9)$ and $12.56 \pm 1.24(N=9)$. respectively. However, at trial 2 , the group with a trial-trial interval of $60 \mathrm{~min}(3.44 \pm 0.29)$ had a significantly increased number of errors, as compared with that with a trial-trial interval of 2 min (2.00 $0.41, P<0.05$, by Student's $t$-test).

Effects of scopolamine and AF64A: Scopolamine at doses over $0.56 \mathrm{mg} / \mathrm{kg}$ significantly and dose-dependently increased error responses (Table 2). However, in trial 1 , none of the doses of scopolamine caused a significant increase in error response in comparison to that of the saline group. On the other hand, scopolamine at 0.56 and $1 \mathrm{mg} / \mathrm{kg}$ also produced a significant increase in the total latency (Table 2).

AF64A, 2.5 nmole, significantly increased the error response (Fig. 3: $F=20.86, P<0.01$. by analysis of variance). The increased error response did not return to the control level by retraining even for 15 days (Fig. 3 ). The total latency $(122.0 \pm 21.1 \mathrm{sec})$ in the $1 \mathrm{st}$ retraining session was significantly increased by the injection of AF64A in comparison with that of control $(64.5 \pm 12.9 \mathrm{sec}, P<0.05)$, but the prolongation of latency returned to control thereafter. AF64A, 5.0 nmale, also markedly increased both the error response and latency. However, in this case, two of the six rats died 2-3 days after surgery. Therefore, these data are not shown in the figure.

\section{Discussion}

Boren (8) first reported a repeated acquisition procedure by the use of an operant apparatus for studying memory in Rhesus monkeys. Since that report, Thompson (9) and other numerous investigators have used similar procedures for studying drug effects on memory in a variety of animal subjects (10-13). However, these procedures require 40-60 sessions of training until attaining a steady state, and require much longer time for training per session because the number of trials within the session are very numerous.

Because of the above described problems, we attempted to use the three-runway apparatus instead of the operant apparatus. The runway apparatus used here is a modification of the one described by Hill who used the apparatus for investigating percent of errors in each choice point. In this apparatus, rats could learn the sequence of correct gates by a training of 6 trials per session, and they reached the steady state at about $5-10$ sessions. From these results, it is apparent that the complection of learning is easily attained with this method in comparison with those of the other methods described above.

In the DMTS procedure, correct response 
(A)
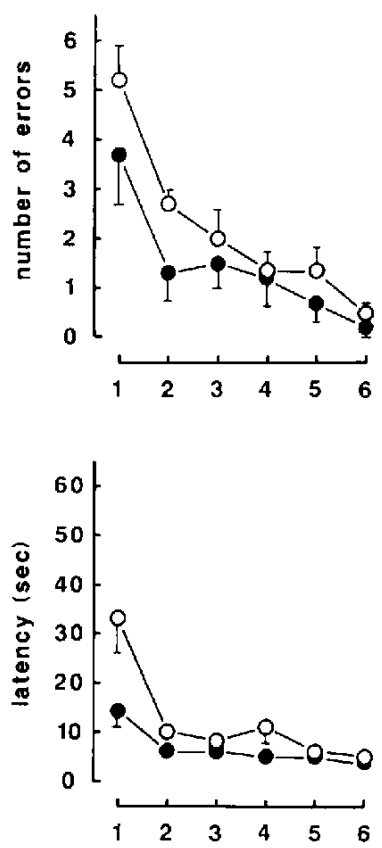

(B)
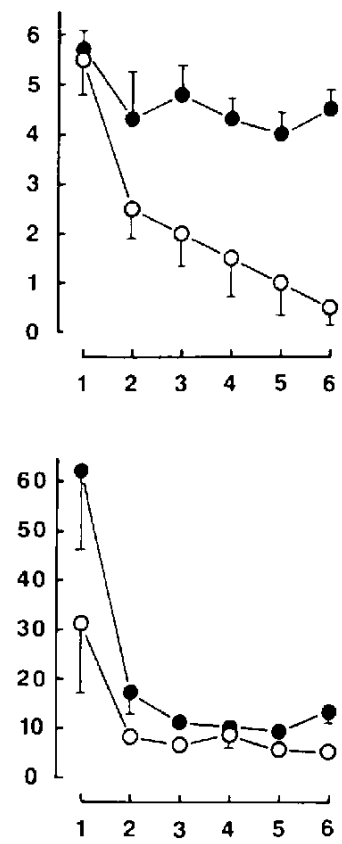

(C)
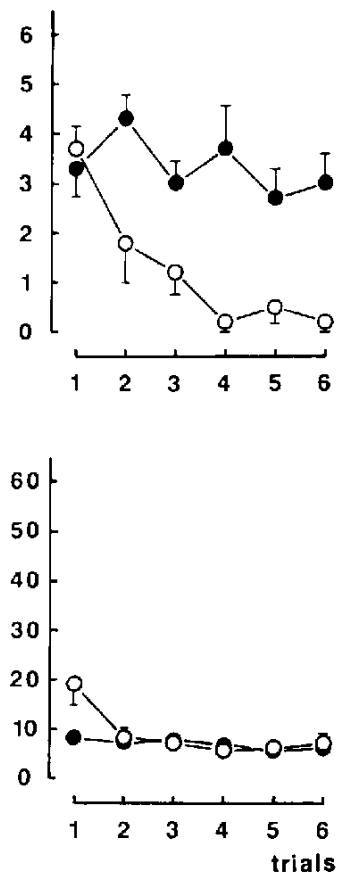

Fig. 3. Effects of AF64A on the number of errors and the latency in the three-panel runway apparatus. Rats were bilaterally injected with saline (O-O) or AF64A, 2.5 nmole (O-O). into the dorsalhippocampus. The trial-trial interval was 2 min. A: pre-microinjection. B: 1 st session (11 days after microinjection of AF64A), C: 15th session (25 days after the injection).

decreased as delay time extended. In our method, however, there was no significant difference among the groups with trial-trial intervals of 2,10 and $60 \mathrm{~min}$. The number of errors was significantly higher only at trial 2 in the group with a trial-trial interval of $60 \mathrm{~min}$. as compared to that with a trial-trial interval of $2 \mathrm{~min}$. This result shows that rats can retain this task for a longer time than the DMTS task (14).

It has been reported that the cholinergic function plays an important role for learning and memory in humans (15-17) and animals $(4,18)$. For example, administration of the cholinergic receptor antagonist scopolamine results in memory impairment in the passive avoidance response (19) and radial maze performance (20). In general, scopolamine and all centrally acting antimuscarinic drugs induce a transient disruption of memory by blocking postsynaptic muscarinic receptors. In our three-panel runway apparatus, scopolamine also produced a disruption of the runway task in a dose-dependent manner.

AF64A, a cholinergic neurotoxin, reduces high affinity transport of choline $(6,7,12)$, the activity of choline acetyltransferase $(7,21$. 22), and contents of acetylcholine (23). In the performance of passive avoidance (22) and radial maze (23), AF64A produces memory deficit. In this experiment by the three-panel runway apparatus, intrahippocampal AF64A induced a memory deficit. Therefore, it is apparent from our results that the working memory is mediated by the cholinergic system in the hippocampus at least. The increased error response induced by AF64A did not recover to the control level even by retraining for 15 days. From this result, it seems difficult for the brain to compensate for this memory deficit. This result agrees with the other reports that intraventricular AF64A induces a permanent deficit of memory (22, 23).

As a conclusion, this experimental procedure using the three panel runway ap- 
paratus would be a useful method for studying working memory, and its working momory deficit is involved at least in a dysfunction of the cholinergic system in the hippocampus.

Acknowledgments: This research was supported in part by a Grant-in-Aid (No. 60570096) for Scientific Research (C) from the Ministry of Education. Science and Culture of Japan and a Grantin-Aid from the Mochida Memorial Foundation for Medical and Pharmaceutical Research to T. Yamamoto. The authors thank the Eisai Company (Tsukuba, Japan) for the generous donation of AF64A.

\section{References}

1 Stanton, M.E., Thomas, G.J. and Brito, G.N.O.: Posterodorsal septal lesions impair performance on both shift and stay working memory tasks. Behav. Neurosci. 98, 405-415 (1984)

2 Teal, J.J. and Evance, H.L.: Effects of DDAVP. a vasopressin analog, on delayed matching behavior in the pigeon. Pharmacol. Biochem. Behav. 17, 1123-1127 (1982)

3 Nagni, S., Krekule, I. and Bures, J.: Radial maze type as a determinant of the choice behavior of rats. J. Neurosci. Methods 1, 343-352 (1979)

4 Watts, J., Stevens, R. and Robinson, C.: Effects of scopolamine on radial maze performance in rats. Physiol. Behav. 26, 845-851 (1981)

5 Mantione, C.R., Fisher, A. and Hanin, I.: The AF64A-treated mouse: possible model for central cholinergic hypofunction. Science $213,579-580$ (1981)

6 Hill, C.J.: Goal gradient, anticipation. and perseveration in compound trial-and-error learning. J. Exp. Psychol. 25, 566-585 (1939)

7 Fisher, A., Mantione, C.R., Abraham, D.J. and Hanin, l.: Long-term central cholinergic hypofunction induced in mice by ethylcholine aziridinium ion (AF64A) in vivo. J. Pharmacol. Exp. Ther. 222, 140-145 (1982)

8 Boren, J.J.; Repeated acquisition of new behavioral chains. Am. Psychol. 17, 421 (1963)

9 Thompson, D.M.: Repeated acquisition as a behavioral base line for studying drug effects. J. Pharmacol. Exp. Ther. 184, 506-514 (1973)

10 Moerschbaecher, J.M. and Thompson, D.M.: Effect of $d$-amphetamine, cocaine and phencyclidine on the acquisition of response sequences with and without stimulus fading. J. Exp. Anal. Behav. 33, 369-381 (1980)

11 Harting, J. and McMillan, D.E.: Effects of pentobarbital and d-amphetamine on the repeated acquisition of response sequences by pigeons. Psychopharmacology (Berlin) 49, 245-248
(1976)

12 Paule, M.G. and McMillan, D.E.: Incremental repeated acquisition in the rat: acute effects of drugs. Pharmacol. Biochem. Behav, 21, 431-439 (1984)

13 Poling, A., Blakely, E., White, W. and Picker, M.: Chronic effects of clonazepam, phenytoin. ethosuximide, and valproic acid on learning in pigeons as assayed by a repeated acquisition procedure. Pharmacol. Biochem. Behav. 24, 1583-1586 (1986)

14 Dunnett, S.B.: Comparative effects of cholinergic drugs and lesions of nucleus basalis or fimbriafornix on delayed matching in rats. Psychopharmacology (Berlin) 87, 357-363 (1985)

15 Bartus, R.T., Dean, R.L., III, Beer, B. and Lippa, A.S.: The cholinergic hypothesis of geriatric memory dysfunction. Science 217, 408-417 (1982)

16 Ghoneim, M.M. and Mewaldt, S.P.: Studies on human memory: the interaction of diazepam. scopolamine, and physostigmine. Psychopharmacology (Berlin) 52, 1-6 (1977)

17 Sitaram, N. and Weingartner, H.: Human serial learning: enhancement with arecholine and choline and impairment with scopolamine. Science 201, 274-276 (1978)

18 Mayers, B. and Domine, F.F.: The effect of cholinergic drugs on spontaneous alternation in rats. Arch. Int. Pharmacodyn. Ther. 150, 522529 (1964)

19 Spignoli, G. and Pepeu, G.: Interactions between oxiracetam, aniracetam and scopolamine on behavior and brain acetylcholine. Pharmacol. Biochem. Behav. 27, 491-495 (1987)

20 Higashida, A. and Ogawa, N.: Differences in the acquisition process and the effect of scopolamine on radia! maze performance in three strains of rats. Pharmacol. Biochem. Behav. 27, 483-489 (1987)

21 Mantione, C.R., Zigmand, M.J., Fischer, A. and Hanin, 1.: Selective presynaptic cholinergic neurotoxicity following intrahippocampal AF64A injection in rats. J. Neurochem. 41, 251-255 (1983)

22 Pope. C.N., Englert, L.F. and Ho, B.T.: Passive avoidance deficits in mice following ethylcholine aziridinium chloride treatment. Pharmacol. Biochem. Behav. 22, 297-299 (1985)

23 Jarrard, L.E., Kart, J.G., Meyerhoff, J.L. and Levy, A.: Behavioral and neurochemical effects of intraventricular AF64A administration in rats. Pharmacol. Biochem. Behav. 21, 273-280 (1984) 